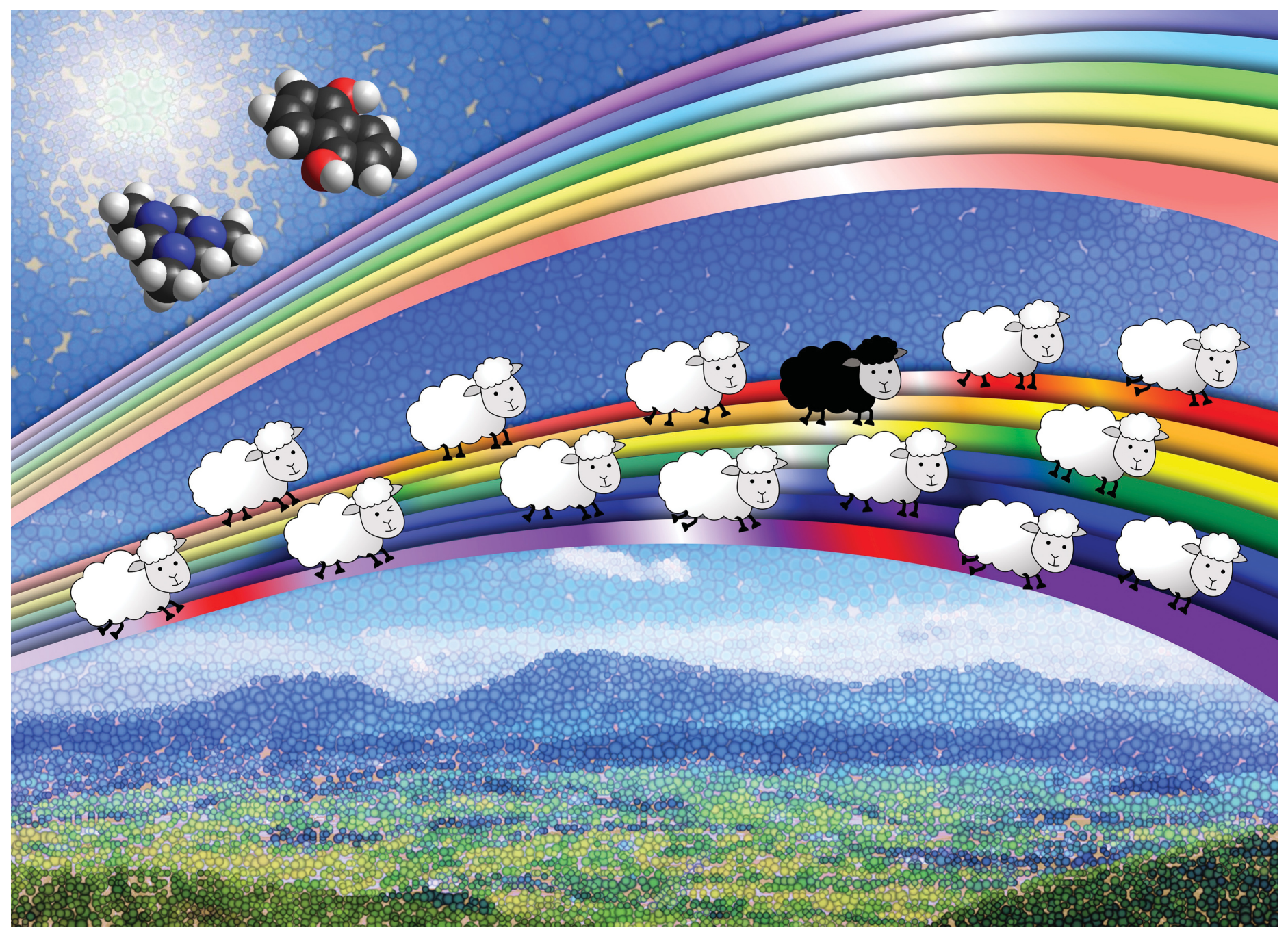

Showcasing research from Professor Makoto Takafuji's laboratory, Faculty of Advanced Science and Technology, Kumamoto University, Kumamoto, Japan.

Thermally stable high-contrast iridescent structural colours from silica colloidal crystals doped with monodisperse spherical black carbon particles

The saturation of structural colors from uniform silica colloids is remarkably improved by simply mixing with $0.1 \mathrm{wt} \%$ or more of monodisperse spherical black nanoparticles, which are facilely synthesized by the carbonization of monodisperse $\pi$-conjugated polymer nanoparticles. The obtained structural colors exhibit not only angle-dependent iridescent colors but also high heat stability up to $350^{\circ} \mathrm{C}$. The art expresses that a "Black sheep" as a maverick makes it possible to draw a rainbow arch in the sky of the Aso volcanic mountains.

\section{As featured in:}

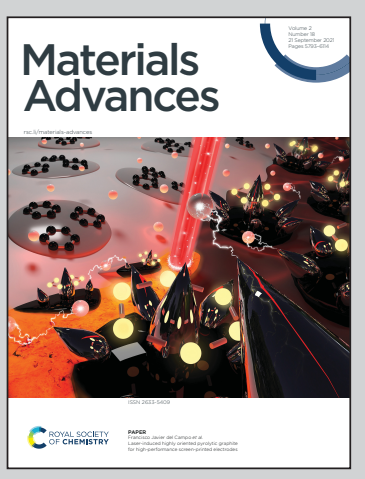

See Makoto Takafuji et al., Mater. Adv., 2021, 2, 5935. 


\section{Check for updates}

Cite this: DOI: 10.1039/d1ma00523e

\title{
Thermally stable high-contrast iridescent structural colours from silica colloidal crystals doped with monodisperse spherical black carbon particles $\dagger$
}

\author{
Kosuke Nakamae, ${ }^{a}$ Nanami Hano, (D) ${ }^{a}$ Hirotaka Ihara (DD ${ }^{\text {ab }}$ and Makoto Takafuji (D) *a
}

\begin{abstract}
Monodisperse black carbon nanoparticles (average diameters: 272 and $511 \mathrm{~nm}$ ) are prepared by the carbonization of monodisperse spherical $\pi$-conjugated polymer particles. Meanwhile, silica nanoparticles of different sizes are prepared by a conventional sol-gel process on the basis of the Stöber method. The cast films fabricated from aqueous dispersion of silica nanoparticles show size-dependent iridescent structural colours of blue $(212 \mathrm{~nm})$, green $(240 \mathrm{~nm})$, yellow $(261 \mathrm{~nm})$, and red $(270 \mathrm{~nm})$. Remarkably, these structural colours show enhanced saturation when black carbon nanoparticles are mixed with a low ratio, such as $1 \mathrm{wt} \%$. The reflection UV-vis spectra indicate that adding carbon particles causes an extreme reduction of reflectance in the visible wavelength region, while the peaks of the structural colours become enhanced in height with almost no shift. Scanning electron microscopy observations suggest that the carbon nanoparticles are well dispersed in the colloidal crystal films of silica nanoparticles but do not disturb the array arrangement. Hence, the iridescence of structural colour is retained. The angle-dependent reflectance spectra of the carbon nanoparticle-doped colloidal crystals mostly agree with theoretical predictions. Since the maverick carbon nanoparticles are thermally stable, the highly saturated structural colours persist up to $350{ }^{\circ} \mathrm{C}$.
\end{abstract}

Received 16th June 2021 Accepted 24th June 2021

DOI: $10.1039 / \mathrm{d} 1 \mathrm{ma} 00523 \mathrm{e}$

rsc.li/materials-advances
However, these nanoparticles are mostly white, and therefore, the obtained structural colours are very pale because of incoherent multiple scattering of light from amorphous regions in the colloidal array. Some researchers tried to enhance the contrast of structural colours by adding black-coloured materials. ${ }^{13-28}$ For instance, adding a small amount of carbon black powder to a colloidal crystal of polystyrene nanoparticles reduced the incoherent scattering considerably. ${ }^{16-22}$ A black coating on the nanoparticles could also increase the saturation of structural colours. ${ }^{23-28}$ As a result, effective improvements have been made in various structural colours (from blue to red) based on the size, refractive index, and packing structure of nanoparticles. However, in both strategies mentioned above, the introduction of black-coloured materials was also detrimental to the iridescent colour effect by disturbing the particle arrangement in the colloidal crystal.

Recently, we reported a facile preparation of monodisperse spherical particles based on $\pi$-conjugated polymers in a way similar to precipitation polymerization..$^{29-31}$ The particulation process including polymerization and crosslinking reactions is carried out by simply mixing in solution an aromatic compound with multiple phenolic groups (such as dihydroxy naphthalene (DHN) and dihydroxy anthracene (DHA)) with a nitrogen-heterocycle, such as 1,3,5-trimethyl-1,3,5-triazinane 
(TMTA) and hexamethylenetetramine (HMTA). ${ }^{29-31}$ The size of the obtained particles can be easily tuned from tens of nanometres to a few micrometres by changing the reaction solvent and temperature. Depending on the type of phenolic aromatics, the particle colour ranges from pale yellow to dark green, indicating that the $\pi$-conjugation structure is extended in the polymerization process. Carbonization of these particles proceeds at a relatively low temperature, and the particles become mostly black afterwards. For example, the particles prepared from 1,5-DHN with TMTA were mostly black after heat treatment at $600{ }^{\circ} \mathrm{C}$, with a reflection of less than $3 \%$ in the visible region. With a precisely controlled size, it seems possible to use these black particles as doping materials to adjust the lattice space of a colloidal photonic crystal.

Herein, we apply monodisperse spherical black carbon nanoparticles with varied sizes to control the iridescent structural colours from a silica colloidal crystal. We also investigate the heat resistance of the structural colour from the doped photonic crystals. Although structural colours expressed by photonic crystals are already known to have strong light resistance, there have been very few studies on the heat resistance of artificial structural colours.

\section{Results and discussion}

\section{Preparation of colloidal silica nanoparticles and black carbon nanoparticles}

Monodisperse spherical colloidal silica particles with different diameters were prepared according to previous reports based on the Stöber method. ${ }^{32,33}$ Field emission scanning electron microscopy (FE-SEM) images of the silica nanoparticles are shown in Fig. S1 (ESI $\dagger$ ). Based on the statistical analysis of several hundred particles in the FE-SEM images, the average size $(d)$ and the coefficient of variation (CV) were determined to be $212(\mathrm{CV}=3.7 \%$, abbreviated as Wp1), $240(\mathrm{CV}=4.1 \%, \mathrm{Wp} 2)$, $261(\mathrm{CV}=3.6 \%, \mathrm{Wp} 3)$, and $270 \mathrm{~nm}(\mathrm{CV}=3.3 \%$, Wp4 $)$ (Table S1, $\mathrm{ESI} \dagger)$.

According to our previous reports, the $\pi$-conjugated polymer nanoparticles were prepared by precipitation polymerization of 1,5-DHN crosslinked with 1,3,5-trimethyl-1,3,5-triazinane (TA) in a mixture of ethanol and ethylene glycol. ${ }^{29,30}$ In this study, the synthesized polymer particles had two sizes of 340 (abbreviated as Bp1) and $627 \mathrm{~nm}$ (Bp2) (Table S2, ESI $\dagger$ ). These polymer particles were then carbonized at $600{ }^{\circ} \mathrm{C}$ for $2 \mathrm{~h}$ in a $\mathrm{N}_{2}$ gas atmosphere, after which their colour became almost black (see the insets of Fig. 1a). The diameters of the carbonized nanoparticles were reduced to 272 ( $\mathrm{CV}=6.8 \%$, abbreviated as Bp1-h) and $511 \mathrm{~nm}(\mathrm{CV}=5.9 \%$, Bp2-h) (Fig. S2, ESI $\dagger)$, accompanied by a weight loss of approximately $50 \%$. The carbon content increased concurrently with the blackening, suggesting that the $\pi$-conjugated system was extended in these nanoparticles. We have reported that the $\mathrm{G}$ band peak in the Raman spectrum of polymer nanoparticles increases at higher heat-treatment temperatures. ${ }^{29}$ Furthermore, it was confirmed that the reflectance of the polymer nanoparticles in the visible
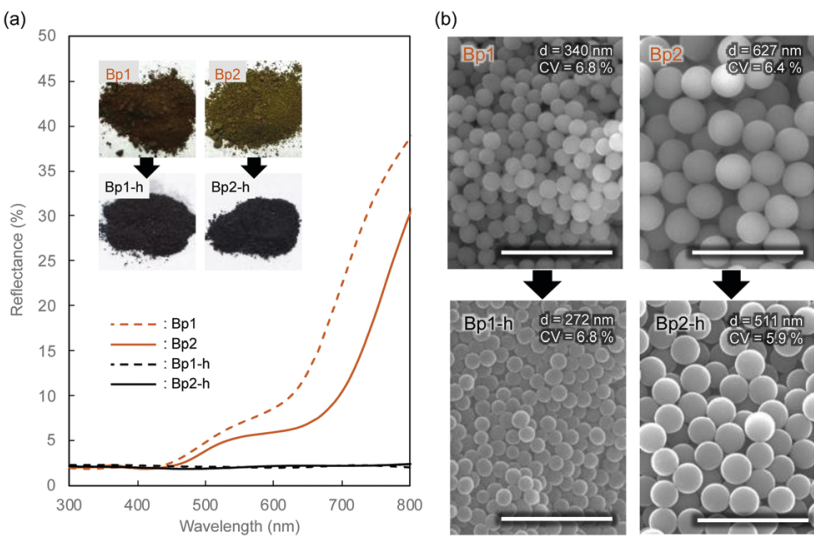

Fig. 1 (a) Diffuse reflectance UV-vis spectra and (b) FE-SEM images of $\pi$-conjugated polymer nanoparticles before (Bp1 and Bp2) and after (Bp1-h and $\mathrm{Bp} 2-\mathrm{h}$ ) heat treatment. The insets in (a) are the photographs of the particles. Heat treatment was carried out at $600{ }^{\circ} \mathrm{C}$ under $\mathrm{N}_{2}$ gas for $2 \mathrm{~h}$. Scale bars in (b): $2 \mu \mathrm{m}$.

region (350 to $800 \mathrm{~nm}$ ) decreased to less than $3 \%$ after carbonization (Fig. 1a). The FE-SEM images (Fig. 1b) show that the polymer nanoparticles were spherical and monodisperse, and their shape was well retained after carbonization at $600{ }^{\circ} \mathrm{C}$.

Table 1 summarizes the morphological features and elemental analysis of polymer nanoparticles before (Bp1 and Bp2) and after (Bp1-h and Bp2-h) carbonization. All polymer nanoparticles and black carbon nanoparticles obtained in this study showed high monodispersity, with low CV values (less than $10 \%)$. The spherical shape of the particles was maintained after heat treatment, and their size and weight shrinkages were approximately $20 \%$ and $50 \mathrm{wt} \%$, respectively. After heat treatment, the carbon percentage $(\mathrm{C} \%)$ increased from around $60 \mathrm{wt} \%$ to more than $80 \mathrm{wt} \%$ as the particles blackened. These results indicate that carbonization of the polymer backbone extended the $\pi$-conjugated structure. Because the polymer precipitated due to crosslinking, the chemical structure of the particles could not be fully analysed by spectroscopic methods such as NMR. However, it is expected that the $\pi$-conjugated structure is developed via the formation of the polynaphthoxazine network. ${ }^{34-36}$ We plan to further investigate the chemical structure of the polymer nanoparticles using soluble polymer networks with less crosslinking, and the results will be discussed elsewhere.

Table 1 Size and elemental analysis of the $\pi$-conjugated polymer nanoparticles before and after heat treatment $\left(600{ }^{\circ} \mathrm{C}, 2 \mathrm{~h}\right)$

\begin{tabular}{llllllr}
\hline & & \multicolumn{5}{c}{ Elemental analysis } \\
\cline { 5 - 7 } Name & Size $^{a}(\mathrm{~nm})$ & $\mathrm{CV}^{a}(\%)$ & $\mathrm{C} \%$ & $\mathrm{H} \%$ & $\mathrm{~N} \%$ & $\mathrm{C} / \mathrm{N}$ \\
\hline Bp1 & 340 & 6.8 & 58.8 & 4.8 & 7.7 & 7.6 \\
Bp2 & 627 & 6.4 & 60.3 & 5.0 & 6.9 & 8.7 \\
Bp1-h & 272 & 6.8 & 82.2 & 1.9 & 4.4 & 18.7 \\
Bp2-h & 511 & 5.9 & 86.1 & 1.8 & 2.1 & 41.0
\end{tabular}

${ }^{a}$ Average size and coefficient of variations (CVs) were calculated from more than 200 particles in the FE-SEM images. 
Doping of black carbon nanoparticles into colloidal crystals of silica nanoparticles

Despite their high carbon content, the carbon nanoparticles were well dispersed in water. These particles carry a positive charge at lower $\mathrm{pH}$ and a negative charge at a higher $\mathrm{pH}$ range, with an isoelectric point at around $\mathrm{pH} 4.5 .^{30}$ This is probably due to the remaining hydrophilic functional groups, such as hydroxyl and amine groups, on the particle surface. ${ }^{30}$ The aqueous mixture of carbon nanoparticles and colloidal silica nanoparticles was sufficiently stable without visible precipitation even after a few hours at ambient temperature. These results indicate that the carbon nanoparticles dispersed well in water in the presence of colloidal silica, which is advantageous for the coating process. After adding the carbon nanoparticles, the dispersion of colloidal silica nanoparticles gradually became grey (Fig. 2a). Films were produced by casting aqueous dispersions of colloidal silica nanoparticles with and without carbon nanoparticles on a glass plate and drying at $60{ }^{\circ} \mathrm{C}$. The obtained films (Fig. 2b) showed iridescent structural colours corresponding to the size of silica particles. In Fig. $2 b$, films of silica nanoparticles (Wp2, $d=240 \mathrm{~nm}$ ) incorporating 272 (Bp1-h) and $511 \mathrm{~nm}$ (Bp2-h) carbon nanoparticles showed enhanced colour saturation. Surprisingly, white light scattered from the film surface decreased with an increasing ratio of the carbon nanoparticles, and the saturation of structural colours increased accordingly. Therefore, after adding the carbon nanoparticles, the film reflectance (background reflection) was reduced over the entire visible light region, thereby highlighting the structural colours from the colloidal crystal. At the same weight percentage, carbon nanoparticles of both sizes

(a)

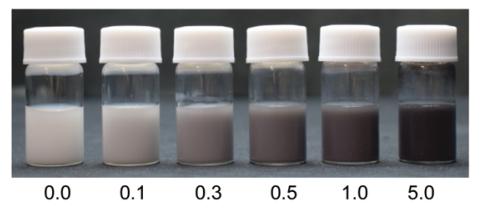

Bp1-h / Wp2 (wt\%)

(b)

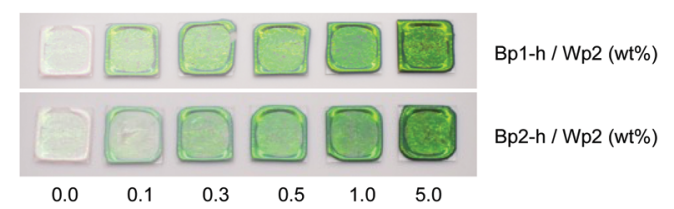

(c)

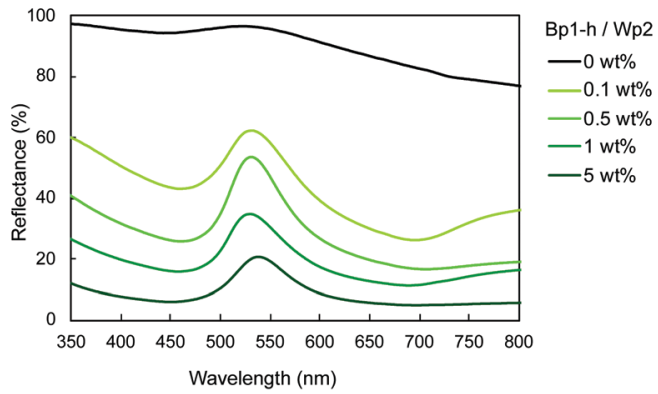

Fig. 2 (a) Photographs of aqueous dispersions of $\mathrm{Wp} 2$ mixed with different amounts of Bp1-h, (b) cast films of Wp2 mixed with different amounts of Bp1-h and Bp2-h. (c) Diffuse reflectance UV-vis spectra of the cast films containing Wp2 and Bp1-h. have similar efficiency in reducing the background reflection, and there was almost no broadening in the reflection peak. This visible difference was further quantified using the reflectance UV-vis spectrum of the cast film (Fig. 2c and Fig. S3, $\mathrm{ESI} \dagger$ ). Indeed, there was a drastic reduction in the reflectance of visible light upon adding the carbon nanoparticles, while the peak height at the wavelength corresponding to the structural colour was relatively enhanced. Meanwhile, there was almost no change in the wavelength of the structural colour after doping with the black carbon particles, indicating that the ordered structure of the colloidal crystal was not disturbed.

A similar enhancement of structural colours by adding a black-coloured component was reported in systems based on artificial colloidal crystals as well as in nature. ${ }^{15-28}$ Most of those studies employed black-coloured coating ${ }^{22-28}$ or used a black material as the background. ${ }^{13}$ A previous study suggested that the black materials improve the saturation of structural colours by absorbing scattered light in a broad wavelength range. ${ }^{14}$ A similar effect may be at work here to cause the improved saturation. Fig. 3a shows the FE-SEM images of cast films prepared from Wp2 mixed with BP1-h or BP2-h. It is obvious that the black carbon nanoparticles were dispersed well in the matrix of the silica colloidal crystal without seriously damaging the latter's crystal structure (Fig. S4 and S5, ESI $\dagger$ ). As far as we know, this is the first example of significant saturation enhancement in the structural colours from a white colloidal crystal by doping of a small amount of carbon nanoparticles as "maverick". It is noteworthy that the saturation could be easily controlled by the doping amount. Fig. 3b shows that Bp1-h and Bp2-h had negatively charged surfaces and were well dispersed in deionized water, and that the silica nanoparticles (Wp2) were also negatively charged in a wide $\mathrm{pH}$ range. Thus, the electrostatic repulsion between the particles helps in maintaining the array arrangement in colloidal crystals after casting and
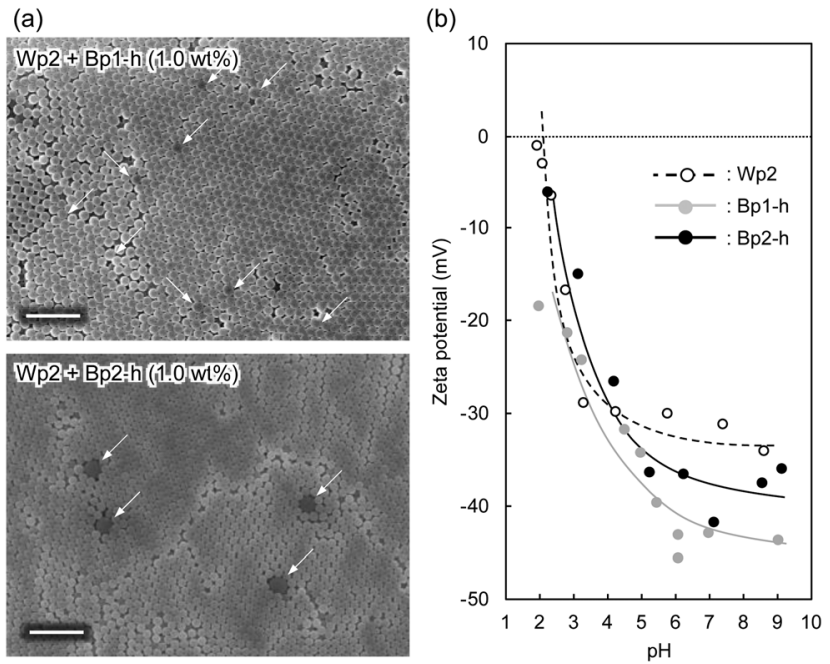

Fig. 3 (a) FE-SEM images of the colloidal crystal of silica nanoparticles (Wp2) with 1 wt\% black carbon nanoparticles (Bp1-h and Bp2-h). Scale bars: $2 \mu \mathrm{m}$. (b) Zeta potentials of the aqueous dispersions of Wp1, Bp1-h, and $\mathrm{Bp} 2-\mathrm{h}$ in a wide $\mathrm{pH}$ range. 
prevents the particle agglomeration. As shown in Fig. S6 (ESI $\dagger$ ), the characteristics peaks for phenolic compound $(\mathrm{O}-\mathrm{H}$ stretching $\left(3600-3200 \mathrm{~cm}^{-1}\right), \mathrm{C}=\mathrm{C}$ stretching $\left(1660 \mathrm{~cm}^{-1}\right), \mathrm{C}-\mathrm{O}$ stretching $\left.\left(1105 \mathrm{~cm}^{-1}\right)\right)$, and methylene groups $(\mathrm{C}-\mathrm{H}$ stretching (2923, and $\left.2856 \mathrm{~cm}^{-1}\right)$ ) were observed in the diffuse reflectance FT-IR spectra of Bp1-h and Bp2-h. Furthermore, new bands appeared at 1733 , and $1720 \mathrm{~cm}^{-1}$ that correspond to the $\mathrm{C}=\mathrm{O}$ stretching of the carboxylic group. It is estimated that carboxylic acid groups are generated on carbon nanoparticles during the synthetic process. Further investigation is needed to clarify the crosslinked polymer network structure.

Fig. 4 plots two parameters in the diffuse reflectance UV-vis spectra of the colloidal crystals, namely the baseline reflectance and the relative peak intensity (" $a$ " and " $b / c$ " in the inset, respectively), against the concentration of the added carbon nanoparticles. Both parameters change according to the doping level. After adding only $1 \mathrm{wt} \%$ carbon nanoparticles (Bp1-h), the value of $a$ decreased from $84 \%$ to $10 \%$ and that of " $b / c$ " increased from 0.06 to 0.70 . It is considered that the uniformly dispersed carbon nanoparticles in the colloidal crystals effectively absorbed light in a wide wavelength range, except for that reflected selectively by the colloidal crystal. When we used larger carbon nanoparticles (Bp2-h), the reduction in baseline reflectance was similar, but the enhancement in the relative peak height was less than that of Bp1-h. We emphasize that only $1 \mathrm{wt} \%$ carbon nanoparticles are enough to enhance the saturation of the colloidal crystal-based structural colour. The structural colours remained iridescent after adding the carbon nanoparticles because the latter were doped in the lattice of the colloidal array without interfering with the original array structure. The angular dependency of iridescent structural colour was visually confirmed (Fig. 5a). Visually, the structural colours of the cast films prepared from Wp1 without $(0 \mathrm{wt} \%)$ and with different amounts (0.1-5.0 wt\%) of Bp1-h showed changes similar to those in Fig. 2b, from emerald green to cobalt blue
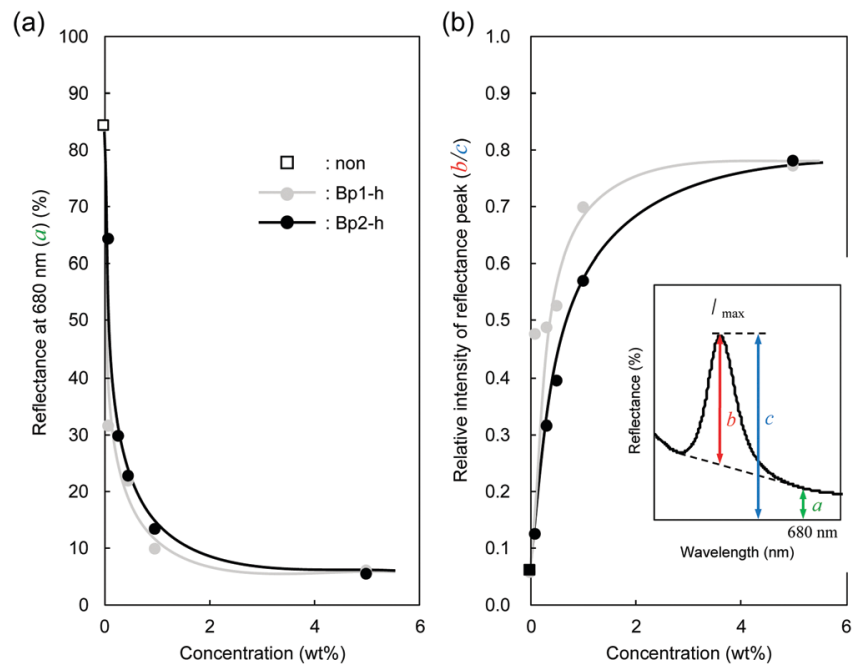

Fig. 4 (a) Baseline reflectance $(680 \mathrm{~nm}$, a) and (b) the relative peak intensity at $\lambda_{\max }(b / c)$ after doping black carbon nanoparticles at different concentrations. (a)

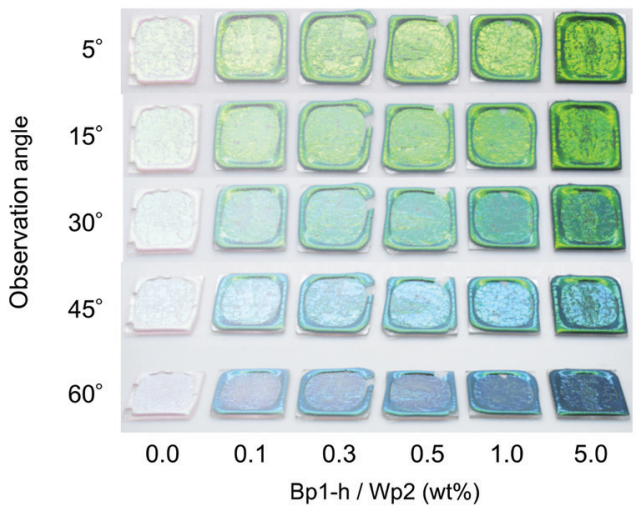

(b)

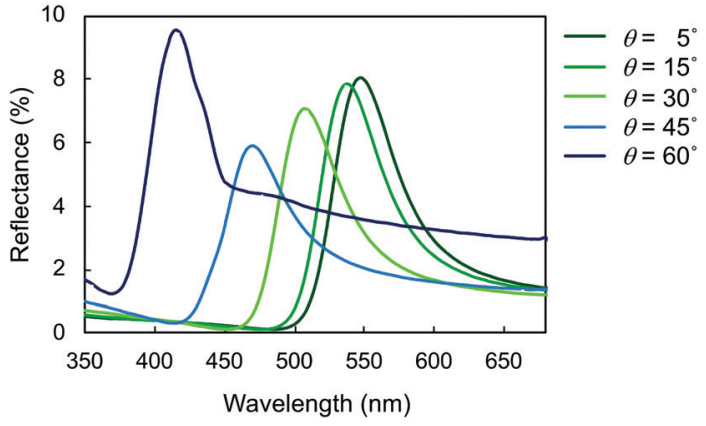

Fig. 5 (a) Photographs at different viewing angles of films prepared from aqueous dispersions of Wp2 with various amounts of Bp1-h. (b) Absolute specular reflectance UV-vis spectra of a cast film containing Wp2 and $5 \mathrm{wt} \%$ of Bp1-h. Both the incident angle and the detection angle were set to the specified angles $(\theta)$.

when the viewing angle changed from the top to the side. These observations were supported by absolute specular reflection UV-vis spectra recorded at different angles (Fig. 5b). The peak top of the reflectance spectrum blue-shifted as the measurement angle increased, from $528.5 \mathrm{~nm}$ at $5^{\circ}$ to $402.5 \mathrm{~nm}$ at $60^{\circ}$ (Fig. 5b). Such a blue-shift of the reflection spectra is commonly observed in colloidal crystal arrays with a long-range ordered structure. ${ }^{10,37,38}$ When a colloidal crystal is prepared on a flat substrate by solution casting, the (111) planes of the facecentred cubic (FCC) lattice are often parallel to the substrate surface. This is the case here according to the FE-SEM images in Fig. 3a. Therefore, the angular dependency could be modelled using eqn (1). ${ }^{10}$

$$
m \lambda=\sqrt{\frac{8}{3}} D\left(\sum_{i} n_{i}^{2} V_{i}-\sin ^{2} \theta\right)^{1 / 2}
$$

where $m$ is the order of diffraction, $D$ is the centre-to-centre distance between nearest spheres, $n_{i}$ and $V_{i}$ are respectively the refractive index and volume fraction of component $i$, and $\theta$ is both the incident light angle and the detection angle to the sample normal. When $m, n_{1}, n_{2}, V_{1}$, and $V_{2}$ take the respective values of $1,1.45,1.00,0.74$, and 0.26 and $\theta$ changes from $5^{\circ}$ to $60^{\circ}$, the calculated value of $\lambda=122 \mathrm{~nm}$ almost agrees with the experimental shift at $5 \mathrm{wt} \%$ carbon nanoparticles (126 nm). Due to the small amount of added carbon nanoparticles, their refractive index was not used in the calculation. (Also, this 
refractive index is difficult to determine due to the strong light absorption, but the value is probably similar to those of phenol formaldehyde resins $(1.55)^{39}$ and benzoxazine resins (1.58 to 1.70). ${ }^{40,41}$ ) Our result indicates that doping black carbon nanoparticles into silica colloidal crystals does not disturb the packing structure, which is advantageous for expressing different iridescent structural colours regardless of the background colour. In contrast, when coating the nanoparticles with a black material, the lattice structure of colloidal crystals is often disrupted due to the uneven coating layer. ${ }^{22,24,25}$ As a result, the angular dependency of the iridescent structural colour was reduced. The baseline reflection increased when increasing $\theta$ to $60^{\circ}\left(2 \theta=120^{\circ}\right)$. The reason is that when light penetration in the colloidal crystals becomes shallower, the doped black carbon nanoparticles also absorb a smaller portion of the scattered light.

We observed similar significant effects of black carbon particles on the structural colours of colloidal crystals formed from silica nanoparticles of different sizes. In Fig. 6a, the cast films prepared from colloidal silica with the diameters of 212 (Wp1), 240 (Wp2), 261 (Wp3), and $270 \mathrm{~nm}$ (Wp4) showed iridescent structural colours of blue, green, yellow, and red, respectively.

The saturation of the structural colours was significantly improved after doping with Bp1-h and Bp2-h, even at a low concentration of $1 \mathrm{wt} \%$. Similar reflection UV-vis spectra with the respective peak tops at 458, 522, 576, and $603 \mathrm{~nm}$ were observed in the cast films from colloidal silica (Wp1, Wp2, Wp3, and Wp4) containing 1 wt\% Bp1-h (Fig. 6b). The same angular dependency occurred in all the colloidal crystals in this study that show different structural colours (Fig. S7, ESI $\dagger$ ).

\section{Heat resistance of colloidal structural colours}

Thermo-gravimetric analysis (TGA) of the $\pi$-conjugated polymer nanoparticles (Bp1) was performed under air and $\mathrm{N}_{2}$ gas atmospheres. The thermograms (Fig. 7a) indicate that under an air

(a)

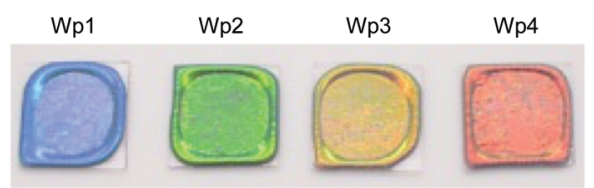

(b)

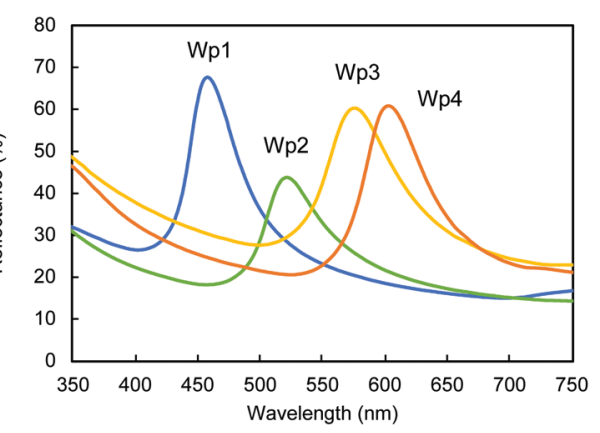

Fig. 6 (a) Photographs of colloidal crystal films of Wp1 (212 nm), Wp2 $(240 \mathrm{~nm})$, Wp3 (261 nm), and Wp4 (270 nm) with $1 \mathrm{wt} \%$ of Bp1-h. (b) Diffuse reflectance UV-vis spectra of films containing each type of colloidal silica nanoparticle and $1 \mathrm{wt} \% \mathrm{Bp} 1-\mathrm{h}$.
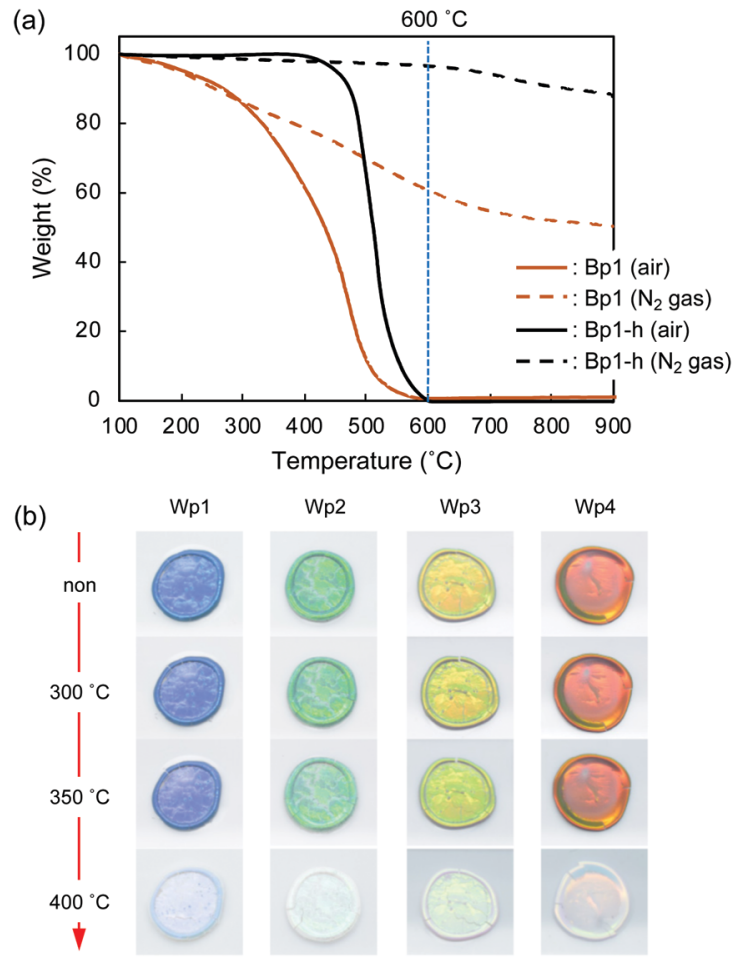

Fig. 7 (a) TGA measurements of $\pi$-conjugated polymer nanoparticles (Bp1) and black carbon nanoparticles (Bp1-h) under air and $\mathrm{N}_{2}$ gas atmospheres. Heating rate: $10{ }^{\circ} \mathrm{C} \mathrm{min}^{-1}$. Gas flow rate: $200 \mathrm{~mL} \mathrm{~min}{ }^{-1}$. (b) Thermal stability of structural colours from the silica nanoparticle (Wp1 to Wp4)-based colloidal crystals doped with 1 wt\% Bp1-h.

atmosphere, the weight loss of Bp1 started at about $100{ }^{\circ} \mathrm{C}$, progressed gradually, and reached the maximum at around $600{ }^{\circ} \mathrm{C}$. Weight loss was also observed under an $\mathrm{N}_{2}$ atmosphere, but nearly $50 \mathrm{wt} \%$ remained even at $900{ }^{\circ} \mathrm{C}$. The weight loss is probably due to the carbonization of the polymer, accompanied by the elimination of low-molecular-weight compounds by decomposition. Bp1-h, which was heat-treated at $600{ }^{\circ} \mathrm{C}$ for $2 \mathrm{~h}$ under vacuum, was thermally more stable than Bp1, as it exhibited almost no weight loss up to $400{ }^{\circ} \mathrm{C}$ even under an air atmosphere. The weight loss started at around $400{ }^{\circ} \mathrm{C}$, and rapidly increased to nearly $100 \%$ up to $600{ }^{\circ} \mathrm{C}$.

The thermal stability of structural colours in the cast film composed of Wp1 and Bp1-h was examined by heat treatment under an air atmosphere. As shown in Fig. 7b, the iridescent structural colour was stable even at $350{ }^{\circ} \mathrm{C}$, indicating a high thermal stability that has not been reported before for structural colours. It is well known that structural colours suffer very little deterioration under light irradiation. The application range of such systems can be significantly expanded by the high heat resistance.

\section{Experimental section}

\section{Materials}

Tetraethyl orthosilicate (TEOS), 1,5-dihydroxy naphthalene (DHN), and 1,3,5-trimethyl-hexahydro-1,3,5-triazinane (TA) were purchased from Tokyo Chemical Industry Co., Ltd. Ammonia solution (25\%), 
ethylene glycol, and ethanol were purchased from Fujifilm Wako Pure Chemical Corporation. All chemicals were used without further purification.

\section{Synthesis of silica nanoparticles}

A mixture of ammonia solution, ethanol, and water (Table S1, ESI $\dagger$ ) was stirred for 20 minutes using a stirring blade at $25{ }^{\circ} \mathrm{C}$. Then, TEOS was quickly added to the mixture and stirred for $4 \mathrm{~h}$. The obtained particles were collected by filtration (PTFE, $0.1 \mu \mathrm{m}$ ) and washed with ethanol. The colloidal silica particles were then redispersed in water, and the dispersion was stored under ambient conditions for the next experiments. The obtained silica nanoparticles were characterized by dynamic light scattering (DLS) measurements and FE-SEM observations.

\section{Synthesis of $\pi$-conjugated polymer nanoparticles and black carbon nanoparticles}

The spherical carbon nanoparticles based on $\pi$-conjugated polymers were prepared according to our previous report. ${ }^{29}$ Briefly, $30 \mathrm{mM}$ of 1,5-DHN and TA were dissolved in a mixture of ethanol and ethylene glycol ( $5: 5$ for the preparation of Bp1, and $8: 2$ for the preparation of $\mathrm{Bp} 2$ ) at room temperature, and the solution was heated to $80{ }^{\circ} \mathrm{C}$ under gentle stirring and kept for $6 \mathrm{~h}$. During heating, the solution colour changed gradually to greenish brown. Microscopic observations indicated that the precipitation of the spherical particles commenced within $30 \mathrm{~min}$, and that the colour change was due to the produced solid component. Afterwards, the solid component was collected by filtration, sufficiently washed with ethanol, and then dried in vacuo. These particles were carbonized by heating at $600{ }^{\circ} \mathrm{C}$ for $2 \mathrm{~h}$ under a nitrogen atmosphere, and their colour changed to black afterwards.

\section{Instrumentation}

Characterization of carbon nanoparticles. The sizes and the surface charges (zeta-potentials) of carbon nanoparticles and colloidal silica nanoparticles were measured in aqueous dispersion using a Zetasizer Nano-ZS (Malvern Panalytical Ltd, Kobe, Japan). The $1 \mathrm{w} / \mathrm{v} \%$ aqueous solution was measured at $25{ }^{\circ} \mathrm{C}$ with an applied voltage of $150 \mathrm{~V}$, and the $\mathrm{pH}$ of the solution was adjusted with $\mathrm{NaOH}$ and $\mathrm{HCl}$ aqueous solutions. Diffuse reflectance FT-IR spectra (DRIFT) were recorded on a JASCO FT/IR 4100 spectrometer equipped with a JASCO DR PRO410-M diffuse reflectance accessory (JASCO. Co., Tokyo, Japan).

Microscopic observations. The carbon nanoparticles and colloidal silica nanoparticles were observed using FE-SEM (SU-8000, Hitachi High-Tech Corporation, Tokyo, Japan). The samples were mounted on adhesive carbon tabs pasted on the SEM pin and coated with osmium using a Filgen OPC80T osmium plasma coater (Filgen, Inc., Nagoya, Japan).

Reflectance spectroscopy. Diffuse reflectance UV-vis spectroscopic measurements were carried out using a UV-visible-NIR spectrophotometer (UV-3600Plus, Shimadzu Co. Ltd, Kyoto, Japan) within 250-800 nm with an integration sphere (ISR-603). Barium sulfate was used as a reference. The absolute specular reflectance was measured using a UV-vis spectrophotometer (V-750ST, JASCO, Tokyo, Japan) equipped with the manual absolute reflectance measurement accessory unit (ARSV-916, JASCO, Tokyo, Japan). No reference was used for the specular reflectance measurements.

Thermogravimetric analysis (TGA). A TG/DTA 6300 thermal analysis system (Hitachi High-Tech Corporation, Tokyo, Japan) was used in this experiment from 30 to $900{ }^{\circ} \mathrm{C}$ at a heating rate of $10{ }^{\circ} \mathrm{C} \mathrm{min}^{-1}$ under flowing nitrogen or air $\left(200 \mathrm{~mL} \mathrm{~min}^{-1}\right)$.

\section{Conclusions}

The iridescent structural colours from silica colloidal crystals showed significantly improved saturation after doping with monodisperse spherical black carbon nanoparticles as "maverick". Carbon nanoparticles with similar sizes to the silica particles were the most effective in suppressing the diffuse reflection from the system in a wide range of visible wavelengths. As a result, the saturation of structural colours could be significantly improved due to the relatively enhanced reflection at the wavelength determined by the size of colloidal silica. Unlike several previous studies producing similar effects by coating white colloidal nanoparticles with black materials, such as polydopamine and carbon black, in this study we simply introduced black maverick particles similar in size and shape to the white silica nanoparticles. Moreover, the saturation could be easily tuned by the amount of added black carbon nanoparticles. Surprisingly, even as little as $1 \mathrm{wt} \%$ maverick nanoparticles were enough to enhance the structural colour. Iridescence of the structural colour was retained because the black carbon nanoparticles did not disturb the array arrangement in the colloidal crystal. Since these maverick nanoparticles are thermally stable, the mixed particle system could maintain highly saturated colours up to $350{ }^{\circ} \mathrm{C}$, in addition to the good light resistance that structural colours are known to possess. Overall, we demonstrated a methodology to produce highly saturated and heat-resistant structural colours.

\section{Conflicts of interest}

There are no conflicts to declare.

\section{Acknowledgements}

This work was supported by Fostering Joint International Research (B), and Grant-in-Aid for Scientific Research (B) of the Japan Society for the Promotion of Science (JSPS).

\section{Notes and references}

1 F. Marlow, Muldarisnur, P. Sharif, R. Brinkman and C. Mendive, Angew. Chem., Int. Ed., 2009, 48, 6212-6233.

2 D. Gur, B. A. Palmer, S. Weiner and L. Addadi, Adv. Funct. Mater., 2017, 27, 1603514. 
3 R. Ahmed, X. Ji, R. M. H. Atta, A. A. Rifat and H. Butt, RSC Adv., 2018, 8, 27111-27118.

4 E. Dufresne, H. Noh, V. Saranathan, S. Mochrie, H. Cao and R. Prum, Soft Matter, 2009, 5, 1792-1795.

5 Q. Li, Q. Zeng, L. Shi, X. Zhang and K. Q. Zhang, J. Mater. Chem. C, 2016, 4, 1752-1763.

6 J. Huang, X. Wang and Z. L. Wang, Nano Lett., 2006, 6, 2325-2331.

7 J. Teyssier, S. V. Saenko, D. Van Der Marel and M. C. Milinkovitch, Nat. Commun., 2015, 6, 1-7.

8 Z. Wang and Z. Guo, Chem. Commun., 2017, 53, 12990-13011.

9 J. Sun, B. Bhushan and J. Tonga, RSC Adv., 2013, 3, 14862-14889.

10 J. Ge and Y. Yin, Angew. Chem., Int. Ed., 2011, 50, 1492-1522.

11 E. Inch, G. Topcu, T. Guner, M. Demirkurt and M. M. Demir, J. Mater. Chem. C, 2020, 8, 12036-12053.

12 H. Ge, Y. Song, L. Jiang and D. Zhu, Thin Solid Films, 2006, 515, 1539-1543.

13 M. Iwata, M. Teshima, T. Seki, S. Yoshioka and Y. Takeoka, Adv. Mater., 2017, 29, 1605050.

14 B. J. D. Forster, H. Noh, S. F. Liew, V. Saranathan, C. F. Schreck, L. Yang, J. G. Park, R. C. Prum, S. G. J. Mochrie, C. S. O'Hern, H. Cao and E. R. Dufresne, Adv. Mater., 2010, 22, 2939-2944.

15 Y. Zhang, P. Han, H. Zhou, N. Wu, Y. Wei, X. Yao, J. Zhou and Y. Song, Adv. Funct. Mater., 2018, 28, 1802585.

16 Y. Takeoka, S. Yoshioka, A. Takano, S. Arai, K. Nueangnoraj, H. Nishihara, M. Teshima, Y. Ohtsuka and T. Seki, Angew. Chem., Int. Ed., 2013, 52, 7261-7265.

17 K. Katagiri, Y. Tanaka, K. Uemura, K. Inumaru, T. Seki and Y. Takeoka, NPG Asia Mater., 2017, 9, e355.

18 Y. Takeoka, Chem. Commun., 2018, 54, 4905-4914.

$19 \mathrm{Y}$. Hu, D. Yang and S. Huang, ACS Omega, 2019, 4, 18771-18779.

20 H. Wang, Y. Liu, Z. Chen, L. Sun and Y. Zhao, Sci. Adv., 2020, 6, eaay1438.

21 Y. Zhang, B. Dong, A. Chen, X. Liu, L. Shi and J. Zi, Adv. Mater., 2015, 27, 4719-4724.

22 M. Teshima, T. Seki and Y. Takeoka, Chem. Commun., 2018, 54, 2607-2610.
23 A. Kawamura, M. Kohri, G. Morimoto, Y. Nannichi, T. Taniguchi and K. Kishikawa, Sci. Rep., 2016, 6, 33984.

24 M. Kohri, Y. Tamai, A. Kawamura, K. Jido, M. Yamamoto, T. Taniguchi, K. Kishikawa, S. Fujii, N. Teramoto, H. Ishii and D. Nagao, Langmuir, 2019, 35, 5574-5580.

25 M. Kohri and Sci Technol, Adv. Mater., 2021, 21, 833-848.

26 X. Yang, D. Ge, G. Wu, Z. Liao and S. Yang, ACS Appl. Mater. Interfaces, 2016, 8, 16289-16295.

27 D. Yang, W. Luo, Y. Huang and S. Huang, ACS Omega, 2019, 4, 528-534.

28 P. Liu, J. Chen, Z. Zhang, Z. Xie, X. Du and Z. Gu, Nanoscale, 2018, 10, 3673-3679.

29 A. Murakami, H. Noguchi, Y. Kuwahara, M. Takafuji, S. Nozato, R. D. Sun, A. Nakasuga and H. Ihara, Chem. Lett., 2017, 46, 680-682.

30 N. Hano, M. Takafuji, H. Noguchi and H. Ihara, ACS Appl. Nano Mater., 2019, 2, 3597-3605.

31 N. Yamada, H. Noguchi, Y. Orimoto, Y. Kuwahara, M. Takafuji, S. Pathan, R. Oda, A. M. Rahimli, M. A. Ramazanov and H. Ihara, Chem. - Eur. J., 2019, 25, 10141-10148.

32 E. D. E. R. Hyde, A. Seyfaee, F. Neville and R. MorenoAtanasio, Ind. Eng. Chem. Res., 2016, 55, 8891-8913.

33 W. Stöber, A. Fink and E. Bohn, J. Colloid Interface Sci., 1968, 26, 62-69.

34 T. Uyar, Z. Koyuncu, H. Ishida and J. Hacaloglu, Polym. Degrad. Stab., 2008, 93, 2096-2103.

35 W. Zhang, P. Froimowicz, C. R. Arza, S. Ohashi, Z. Xin and H. Ishida, Macromolecules, 2016, 49, 7129-7140.

36 C. R. Arza, P. Froimowicz, L. Han, R. Graf and H. Ishida, Macromolecules, 2017, 50, 9249-9256.

37 J. B. Kim, S. Y. Lee, J. M. Lee and S.-H. Kim, ACS Appl. Mater. Interfaces, 2019, 11, 14485-14509.

38 Y. J. Lee and P. V. Braun, Adv. Mater., 2003, 15, 563-566.

39 R. B. Seymour and C. E. Carraher Jr, Structure-Property Relationships in Polymers, Plenum Press, New York, 2012.

40 H. C. Chang, C. H. Lin, Y. W. Tian, Y. R. Feng and L. H. Chan, J. Polym. Sci., Part A: Polym. Chem., 2012, 50, 2201-2210.

41 M. C. Tseng and Y. L. Liu, J. Polym. Sci., Part A: Polym. Chem., 2010, 51, 4020-4026. 